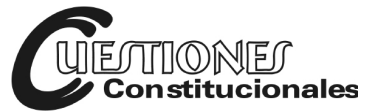

Revista Mexicana de Derecho Constitucional

Núm. 32, enero-junio 2015

\title{
LA INTERPRETACIÓN CONFORME Y SU IMPACTO EN LOS JUECES MEXICANOS
}

\author{
INTERPRETATION ACCORDING TO THE CONSTITUTION \\ AND ITS IMPACT ON MEXICAN JUDGES
}

\section{Pedro Antonio EnRÍQUeZ SOTO*}

RESUMEN: El control difuso de constitucionalidad históricamente anulado por el Poder Judicial federal resurge en materia de derechos humanos por decisión del constituyente permanente de la mano de una serie de vicisitudes y retos para los operadores jurisdiccionales del país. De entrada, la nula experiencia del juzgador en la interpretación del texto constitucional y la arraigada corriente iuspositivista exige actualizarse en los conceptos del derecho procesal constitucional, para poder dar el salto de juzgador ordinario a garante de la supremacía constitucional. El principio de interpretación conforme a la Constitución y otros conceptos que en el presente artículo se exponen son indispensables para guiar la actuación del operador jurisdiccional como defensores de los derechos humanos. Comprenderlo ayudará a evitar los excesos que puede llegar a generar un activismo jurisdiccional desarticulado, donde la aplicación del control difuso de constitucionalidad pueda servir siempre para desconocer el contenido de cualquier norma.

Palabras clave: control constitucional, derechos humanos, interpretación conforme a la Constitución, presunción de constitucionalidad, interpretación constitucional, argumentación jurídica, control concentrado, control difuso, juzgador mexicano.
ABSTRACT: Historically, the Federal Judicial Branch has annulled the diffuse constitutional control. It came to light again as a result of the permanent legislature's decision; this reappearance is linked to issues related to human rights, creating myriad challenges and vicissitudes for judges in the Country. At the outset, there is null judge's experience related to the interpretation of the constitution's text; and, there is a deeply rooted line of thought, the iuspositivism. This shift requires judges to bring up to date their knowledge related to procedural constitutional law, in this way they will be able to evolve from an ordinary judge to one who will guarantee constitutional supremacy. The principle of interpretation according to the Constitution and other principles that are presented in this paper are essential to guide judges as well as human rights advocates. The understanding of those principles will help to avoid the emergence of an unarticulated judicial activism that may lead to the application of the diffuse constitutional control as a way to strike down any norm.

Descriptors: constitutional control, human rights, interpretation according to the constitution, presumption of constitutionality, constitutional interpretation, legal argumentation, concentrated control, diffuse control, mexican judiciary.

Doctor en derecho por la Universidad Michoacana de San Nicolás de Hidalgo; profesor de tiempo completo de la Unidad Académica de Derecho de la Universidad Autónoma de Nayarit; reconocimiento de perfil Promep; miembro del Sistema Nacional de Investigadores nivel I, Conacyt; presidente del Tribunal Superior de Justicia y de la Sala Constitucional-Electoral del Poder Judicial de Nayarit. 


\section{Planteamiento DEL PROBLEMA}

Las reformas constitucionales en materia de derechos humanos y de amparo de junio de 2011, en México, son consideradas como la transformación jurídica más importante después de la vigencia de la Constitución de 1917. Uno de los aspectos más relevantes de la modificación al artículo 10. constitucional se refiere a la afirmación del constituyente de reiterar, ${ }^{1}$ ya sin cortapisas, la facultad para todas las autoridades, y con especial dedicatoria para los jueces mexicanos, de ser garantes de la supremacía constitucional. Esta insistencia de conceder a la jurisdicción — toda-para ejercer el control difuso de constitucionalidad, negada desde la vigencia de la Constitución del 1917 a los jueces mexicanos por interpretación jurisprudencial de la Corte, está poniendo en serias dificultades a los operadores jurisdiccionales del país para poder entender el alcance y significado del nuevo contenido del artículo 1o. constitucional.

Por una parte, la dificultad radica en la nula experiencia de los jueces ordinarios respecto a la materia constitucional, puesto que, por siempre, su única herramienta de trabajo lo fueron los códigos o leyes para resolver las controversias jurídicas sometidas a su consideración. Por otro lado, y consustancial a la anterior, se encuentran frente a un universo de normas hasta hoy poco usadas para el trabajo jurídico, como lo son la Constitución y los tratados internacionales, que ahora forman parte del material normativo sobre los cuales debe tomarse una decisión judicial para garantizar el respeto a los derechos humanos. Y finalmente, entender el alcance del contenido sustancial de la reforma exige una profunda actualización de conceptos del derecho procesal constitucional, que necesariamente deben formar parte del bagaje profesional de los jueces mexicanos, que permita entender conceptos como "control constitucional", "control de convencionalidad", "control difuso", "interpretación conforme" entre tantos más, necesarísimos para lograr el propósito fundamental que buscó el constituyente con esta reforma.

Es justamente uno de los conceptos de la reforma constitucional de derechos humanos el que se abordará en este estudio, con el propósito de

1 Se afirma reiterar, ya que la facultad de los jueces mexicanos para ejercer el control difuso de constitucionalidad estuvo siempre presente en el artículo 133 de la Constitución; sin embargo, ésta fue suprimida mediante jurisprudencia de la Suprema Corte de Justicia de la Nación, que negó tal posibilidad a los jueces mexicanos que no fueran jueces de amparo. 
exponer los alcances, conceptualización, principios relacionados, naturaleza jurídica, límites y aplicación, del principio de interpretación conforme, que contribuya a su exploración doctrinal y práctica para el trabajo jurídico de jueces y abogados en general.

Si tuviéramos que adjetivar la percepción de los abogados mexicanos con relación a la reforma de derechos humanos, se podría afirmar que existen emociones contradictorias, por una parte los optimistas, los que ven con ella la oportunidad de potencializar los derechos humanos desde el momento mismo en que éstos se defienden en una primera instancia jurisdiccional que tendrá la posibilidad jurídica de protegerlos por encima de la ley meramente ordinaria; es decir, ampliando su protección hacia la Constitución y los tratados internacionales, sin tener que esperar a la instancia salvadora que hasta antes de la referida reforma se encontraba en exclusivas manos de los jueces de amparo. Por otra parte, existe también una corriente de emociones poco o nada convencidas con estas nuevas facultades de los jueces mexicanos, cobijados por el tradicionalismo cómodo que les genera seguir el statu quo, de ser sólo la boca de la ley, como lo sostuvo Montesquieu.

Sin embargo, el riesgo del optimismo puede traer serias consecuencias dañinas al propósito perseguido con la reforma, al no lograrse comprender con claridad que la posibilidad de los jueces para desaplicar una ley ordinaria al caso concreto, en aras de proteger la Constitución, tiene límites o parámetros que deben ser observados por los juzgadores antes de tomar la decisión de inobservar una disposición legal que tilde de inconstitucional: uno de estos límites es la interpretación conforme.

\section{EL ORIGEN DE LA INTERPRETACIÓN CONFORME}

El principio de interpretación conforme tiene su origen en la jurisprudencia de la Corte Suprema de los Estados Unidos, particularmente en el voto formulado por el justice Samuel Chase, en el caso Hylton vs. United States en 1796, quien expresó: "si la Corte tiene tal poder de declarar la inconstitucionalidad, soy libre de declarar que nunca lo ejerceré si no se trata de un caso muy claro". 2

2 Carpio Marcos, Edgar, "Interpretación conforme con la Constitución y las sentencias interpretativas (con especial referencia a la experiencia alemana)", en Ferrer Mac-Gregor, Eduardo y Zaldívar Lelo de Larrea, Arturo (coords.), La ciencia del derecho procesal constitucional. Estudios en homenaje a Héctor Fix-Zamudio en sus cincuenta años como 
Este precedente judicial estadounidense fue reiterado por la jurisdicción de ese país y por la propia doctrina de Hamilton, quien sostuvo que "la función de los tribunales es declarar nulos todos los actos contrarios al sentido evidente de la Constitución". ${ }^{3}$ La expresión "evidente" marca una línea muy clara, que favorece el carácter democrático de la legislación, al considerar que la declaración de inconstitucionalidad sólo puede producirse cuando resulta evidencia contundente de la contrariedad de la norma con la Constitución.

Por su parte, el célebre juez John Marshall sostuvo que "la conformidad de una ley con la Constitución debía decidirse en sentido afirmativo en un caso dudoso, pues no sobre leves implicaciones y vagas conjeturas debe pronunciarse que la legislatura trascendió sus poderes, sino sólo cuando el juez sienta una clara y fuerte convicción sobre la incompatibilidad entre la Constitución y la ley". ${ }^{4}$

Esta línea argumentativa de Marshall la reiteró en el caso Dartmouth College vs. Woodward, al sostener:

Esta Corte no puede ser insensible a la magnitud o a la delicadeza de esta cuestión. Debe examinarse la validez de un acto legislativo; y la opinión del más alto tribunal de derecho de un Estado debe revisarse —una opinión que trae consigo evidencia intrínseca de la diligencia, habilidad e integridad con la que se formó-. En más de una ocasión, esta Corte ha expresado la cautelosa circunspección con la cual se aboca a considerar tales cuestiones, y declarado que en ningún caso dudoso pronunciaría que un acto legislativo es contrario a la Constitución. ${ }^{5}$

La tesis consistente del principio in dubio pro legislatore estadounidense tiene su fundamento principal en la fuerza democrática del legislador, haciendo presumir que éste siempre tiene la intención de respetar los límites

investigador del derecho, México, UNAM, Instituto de Investigaciones Jurídicas, 2008, t. VI, p. 157.

3 El Federalista, trad. de Gustavo R. Velasco, México, Fondo de Cultura Económica, 2000, núm. LXXVIII, p. 331.

4 Sánchez Gil, Rubén, "La presunción de constitucionalidad", en Ferrer Mac-Gregor, Eduardo y Zaldívar Lelo de Larrea, Arturo (coords.), La ciencia del derecho procesal constitucional..., cit., t. VIII, p. 370.

5 Ibidem, p. 371. 
constitucionales y no de transgredirlos, y ante la duda de inconstitucionalidad, la única alternativa de interpretación del juez es interpretar la ley de conformidad con la Constitución, in harmony with the Constitution. De esta forma se evita la expulsión de una norma por meras sospechas de inconstitucionalidad, sino que debe ir más allá de la duda razonable.

El principio de interpretación conforme fue adoptado de igual forma en Europa por el Tribunal Federal Constitucional alemán en 1953, en la decisión Rec. 2, 266, 282 — asistencia a los alemanes sobre el territorio federal — bajo el siguiente argumento: "Una ley no debe ser declarada nula, si puede ser interpretada de acuerdo con la Constitución; pues no sólo hay una presunción a favor de la constitucionalidad de la ley, sino que el principio que aparece en esta presunción exige también, en caso de duda, una interpretación de la ley conforme a la Constitución". ${ }^{6}$

En suma, el principio de interpretación conforme ha tenido una gran aceptación en la jurisprudencia constitucional de diversos países de Europa y América Latina, como en Colombia, ${ }^{7}$ Brasil $^{8}$ y Chile. ${ }^{9}$

En España, el artículo 10.2 de la Constitución dispone: "Las normas relativas a los derechos fundamentales y a las libertades que la Constitución reconoce se interpretarán de conformidad con la Declaración Universal de Derechos Humanos y los tratados y acuerdos internacionales sobre las mismas materias ratificados por España".

Para el caso mexicano, Rubén Sánchez Gil ${ }^{10}$ sostiene que el antecedente del principio de interpretación conforme data de 1940, cuando la Segunda

6 Figueroa Mejía, Giovanni A., Las sentencias constitucionales atipicas en el derecho comparado y en la acción de inconstitucionalidad mexicana, México, Porrúa, 2011, p. 52 .

7 En Colombia, el artículo 4o. de la Constitución establece: "La Constitución es norma de normas. En todo caso de incompatibilidad entre la Constitución y la ley u otra norma jurídica, se aplicarán las disposiciones constitucionales".

8 En la jurisprudencia del Supremo Tribunal Federal, el marco concerniente a la interpretación conforme a la Constitución es el voto del juez Moreira Alves en la Rep. 1417, de 1987: "[La] interpretación de la norma sujeta a control debe partir de una hipótesis de trabajo, la llamada presunción de constitucionalidad, de la cual se extrae que, entre dos entendimientos posibles del precepto impugnado, debe prevalecer el que sea conforme a la Constitución". Véase Da Silva Virgilio, Alfonso, "La interpretación conforme a la Constitución. Entre la trivialidad y la centralización judicial", Cuestiones Constitucionales, Revista Mexicana de Derecho Constitucional, México, núm. 12, enero-junio de 2005, p. 5.

9 Sentencia Rol 309/2000. Citado por Figueroa Mejía, Giovanni A., op. cit., p. 55.

10 Sánchez Gil, Rubén, op. cit., p. 396. 
Sala de Suprema Corte emitió una jurisprudencia que dice: "Las leyes secundarias deben interpretarse armonizándolas con los estatutos constitucionales, porque no se concibe, salvo cuando el texto de ellas sea perfectamente claro y no dé lugar a interpretación, que el legislador haya pretendido establecer una disposición a todas luces anticonstitucional". ${ }^{11}$

El propio Rubén Sánchez Gil afirma:

No obstante las importantes tesis... no se recurrió constantemente a la interpretación conforme, en la adjudicación constitucional mexicana, debido a que el régimen político imperante en la mayor parte del siglo XX resultó en un minimalismo de la Suprema Corte y los demás órganos jurisdiccionales mexicanos, que impidió la formación de una consistente teoría normativa constitucional que desembocara en una interpretación de este tipo. ${ }^{12}$

Coincido con la afirmación anterior, puesto que durante el régimen hegemónico del país hasta la culminación de siglo XX hubo un escaso desarrollo de la jurisprudencia mexicana no sólo en tópicos como la interpretación conforme, sino en la propia renuncia que la Corte hizo a ejercer el control abstracto de constitucionalidad de las leyes, convirtiéndose sólo en un tribunal de legalidad de cierre de la jurisdicción nacional. ${ }^{13}$

La doctrina de interpretación conforme en México es reciente para el caso del Poder Judicial federal, ya que principalmente se da a partir de la reforma constitucional de diciembre de 1994 que confirió facultades propias de tribunal constitucional a la Suprema Corte de Justicia de la Nación, y con ello la posibilidad de ejercer el control abstracto de constitucionalidad de las leyes, por la vía de acción de inconstitucionalidad; es así como se vino a desarrollar con mayor auge la doctrina del principio de interpretación conforme, en las jurisprudencias de la novena época. ${ }^{14} \mathrm{Si}$ ello ocurre en esta

11 LeYes SECUNDARIAS, INTERPRETACIÓN DE LAS. Semanario Judicial de la Federación, quinta época, 2a. sala, t. LVII, p. 2581.

12 Sánchez Gil, Rubén, op. cit., p. 396.

13 Véase Cossío, José Ramón, La teoría constitucional de la Suprema Corte de Justicia, México, Fontamara, 2002. Cossío define el periodo de 1940 a 1994 como minimalismo de la Corte mexicana.

14 INTERPRETACIÓN CONFORME EN ACCIONES DE INCONSTITUCIONALIDAD, CUANDO UNA NORMA ADMITA VARIAS INTERPRETACIONES DEBE PREFERIRSE LA COMPATIBLE CON LA CONSTITUCIÓN. La interpretación de una norma general analizada en acción de inconstitucionalidad, debe partir de la premisa de que cuenta con la presunción de constitucionalidad, lo que se traduce en que cuando una disposición legal admita más de una 
instancia federal, ¿qué podemos esperar de las jurisdicciones ordinarias, léase jueces locales, que tienen frente a sí el reto de ejercer control constitucional, respetando el parámetro de interpretación conforme?

Es con la reforma de junio de 2011 al artículo 1o. constitucional cuando se constitucionaliza el principio de interpretación conforme como criterio interpretativo del texto constitucional en el párrafo segundo, que a la letra dice: "Las normas relativas a los derechos humanos se interpretarán de conformidad con esta Constitución y con los tratados internacionales de la materia favoreciendo en todo tiempo a las personas la protección más amplia".

Como se verá más adelante, este es el reto de los jueces mexicanos: por una parte, ejercer la facultad de inaplicar leyes por ser inconstitucionales, y por otra, realizar esta delicada tarea armonizándola con el criterio de interpretación conforme.

interpretación, debe privilegiarse la que sea conforme a la Constitución Política de los Estados Unidos Mexicanos. Entonces, cuando una norma legal admita distintas interpretaciones, algunas de las cuales podrían conducir a declarar su oposición con la Ley Suprema, siempre que sea posible, la Suprema Corte de Justicia de la Nación optará por acoger aquélla que haga a la norma impugnada compatible con la Constitución, es decir, adoptará el método de interpretación conforme a ésta que conduce a la declaración de validez constitucional de la norma impugnada, y tiene como objetivo evitar, en abstracto, la inconstitucionalidad de una norma; sin embargo, no debe perderse de vista que la acción de inconstitucionalidad es un medio de control que tiene como una de sus finalidades preservar la unidad del orden jurídico nacional, a partir del parámetro constitucional; como tampoco debe soslayarse que tal unidad se preserva tanto con la declaración de invalidez de la disposición legal impugnada, como con el reconocimiento de validez constitucional de la norma legal impugnada, a partir de su interpretación conforme a la Ley Suprema, ya que aun cuando los resultados pueden ser diametralmente diferentes, en ambos casos prevalecen los contenidos de la Constitución. En consecuencia, el hecho de que tanto en el caso de declarar la invalidez de una norma legal, como en el de interpretarla conforme a la Constitución, con el propósito de reconocer su validez, tengan como finalidad salvaguardar la unidad del orden jurídico nacional a partir del respeto y observancia de las disposiciones de la Ley Suprema, este Tribunal Constitucional en todos los casos en que se cuestiona la constitucionalidad de una disposición legal, debe hacer un juicio razonable a partir de un ejercicio de ponderación para verificar el peso de los fundamentos que pudieran motivar la declaración de invalidez de una norma, por ser contraria u opuesta a un postulado constitucional, frente al peso derivado de que la disposición cuestionada es producto del ejercicio de las atribuciones del legislador y que puede ser objeto de una interpretación que la haga acorde con los contenidos de la Ley Suprema, debiendo prevalecer el que otorgue un mejor resultado para lograr la observancia del orden dispuesto por el Constituyente y el órgano reformador de la Norma Suprema. Semanario Judicial de la Federación y su Gaceta, novena época, t. XXVII, febrero de 2008, p. 1343. 


\section{LA CLÁUSULA DE INTERPRETACIÓN CONFORME}

\section{Concepto}

La doctrina constitucional y, como se vio líneas arriba, la jurisprudencia, son unánimes al sostener que el concepto "interpretación conforme" debe ser entendido como la técnica interpretativa de las normas infraconstitucionales que admitiendo dos interpretaciones válidamente posibles, pero contradictorias entre sí, debe preferirse aquélla que haga acorde la norma con la Constitución.

Así, Alfonso Da Silva Virgilio sostiene: "De forma general, cuando se habla de interpretación conforme a la Constitución, se quiere decir con esto que, cuando hay más de una interpretación posible para un dispositivo legal, se debe dar preferencia a aquélla que sea conforme a la Constitución". ${ }^{15}$ En el mismo sentido se pronuncia Paulo Bonavides:

Una norma puede admitir varias interpretaciones. De éstas, algunas conducen al reconocimiento de la inconstitucionalidad, otras sin embargo consienten en tomarla por compatible con la Constitución. El intérprete, adoptando el método propuesto [la interpretación conforme a la Constitución], tiene que inclinarse por esta última salida o vía de solución. La norma, interpretada "conforme a la Constitución", será por lo tanto considerada constitucional. ${ }^{16}$

Por su parte, Carpio Marcos explica:

la necesidad de interpretar la ley conforme con la Constitución es una técnica inmanente o consustancial a la justicia constitucional, más que un criterio de interpretación de normas, puesto que impone la regla a todo juez constitucional de no declarar la invalidez de una disposición legislativa si es que ésta pueda ser interpretada cuando menos en dos sentidos posibles, siendo al menos uno de ellos conforme con la Constitución. ${ }^{17}$

Eduardo Ferrer Mac-Gregor, al referirse al concepto de interpretación conforme, dice:

Da Silva Virgilio, Alfonso, op. cit., p. 4.

Idem.

17 Carpio Marcos, Edgar, op. cit., p. 160. 
En términos generales, podríamos sintetizarla como la técnica hermenéutica por medio de la cual los derechos y libertades constitucionales son armonizados con los valores, principios y normas contenidos en los tratados internacionales sobre derechos humanos signados por los Estados, así como por la jurisprudencia de los tribunales internacionales (y en ocasiones otras resoluciones y fuentes internacionales), para lograr su mayor eficacia y protección. ${ }^{18}$

De esta forma, la cláusula de interpretación conforme parte del principio de que una norma infraconstitucional, al examinarse su constitucionalidad, puede admitir varias interpretaciones válidamente posibles, y de éstas, algunas conducen al reconocimiento de inconstitucionalidad; otras, en cambio, admiten la constitucionalidad de la norma, y el intérprete debe preferir esta última, a efecto de evitar la expulsión de la norma del sistema jurídico.

\section{Naturaleza jurídica del principio}

Para ubicar la naturaleza jurídica del principio de interpretación conforme es necesario precisar que cuando se habla de este concepto no se está hablando de interpretación constitucional, pues no es la Constitución la que debe ser interpretada en conformidad consigo misma, sino con las leyes infraconstitucionales. ${ }^{19}$ La interpretación de la ley conforme a la Constitución no es un criterio de interpretación de la Constitución, como lo pueden ser el de unidad, concordancia práctica, eficacia integradora, etcétera. ${ }^{20}$ Tampoco puede ser un criterio de interpretación de la ley, aunque necesariamente para realizar el examen de constitucionalidad de la norma infraconstitucional es necesario recurrir a los métodos interpretativos ordinarios para conocer el alcance de la disposición normativa.

Entonces, ¿cuál es la naturaleza jurídica de la interpretación conforme? Se trata de un principio de corte constitucional que obliga a todas las autoridades a interpretar las normas inferiores de derechos humanos buscando la concordancia, armonización y compatibilidad más cercana a la norma

18 Interpretación conforme y control difuso de convencionalidad, el nuevo paradigma para el juez mexicano, México, UNAM, Instituto de Investigaciones Jurídicas, p. 358. http://www.conatrib.org. $m x / h t m l / P a n e l e s / P a n e l e s / P a n e l V I I I I n t e r p r e t a c i \% C 3 \% B 3 n C o$ nformeControlDifusoConvencionalidad_EduardoFerrer.pdf.

19 Da Silva, Virgilio Alfonso, op. cit., p. 4.

20 Carpio Marcos, Edgar, op. cit., p. 159. 
constitucional, para evitar la expulsión de normas por la simple sospecha de inconstitucionalidad.

Es decir, se impone un canon o parámetro de observancia del juez para rechazar cualquier interpretación de la ley que riña con la Constitución, si la misma ley puede ser interpretada en forma armoniosa o conforme con la ley fundamental. Luis Aguilar de Luque afirma que "el principio de interpretación conforme puede ser calificado como un criterio de resolución de conflictos internormativos". ${ }^{21}$

\section{Contenido del principio}

Para el caso mexicano, como se ha expresado líneas arriba, la constitucionalización del principio de interpretación conforme se dio con la reforma a derechos humanos de junio de 2011, al incorporarse este criterio interpretativo al segundo párrafo del artículo 1o., dejándose atrás lo que de forma tibia venía realizando la Suprema Corte de Justicia en la novena época jurisprudencial.

Ahora bien, el contenido del segundo párrafo del artículo 1o. constitucional se puede identificar con los siguientes elementos:

1. Los sujetos vinculados con el principio interpretativo lo constituyen todas las autoridades dentro del ámbito de sus respectivas competencias, llámese de carácter administrativo, legislativo o jurisdiccional, cuando tengan que interpretar normas relativas a los derechos humanos; no es una facultad exclusiva de jueces, sino de todas aquellas autoridades en el ejercicio natural de sus funciones; pero también cabría la posibilidad de los propios particulares, al momento de hacer planteamientos de defensa de los derechos humanos ante alguna autoridad.

2. Es un criterio vinculante para todas las autoridades, las cuales no pueden negarse a su observancia; se trata de una técnica interpretativa obligatoria no disponible para el sujeto vinculado; ello, a fin de evitar que la autoridad haga uso discrecional de ella.

3. Teleología del principio. El criterio de interpretación conforme busca preservar la norma jurídica impugnada de inconstitucional, con el fin de evitar el horror vacui, evitar con ello caer en un campo lagunoso; al mismo tiempo reconoce la voluntad democrática del legislador de respe- 
tar los parámetros constitucionales al momento de crear la norma. Por el contrario, la interpretación conforme a la Constitución es un instrumento para el mantenimiento de una norma que siendo parcialmente inconstitucional no es declarada nula, al poder ser interpretada en concordancia con la Constitución. ${ }^{22}$ Se trata pues de buscar por los medios interpretativos naturalmente posibles la armonización de la norma con la norma fundamental, preservando la obra legislativa y por consiguiente preservando el derecho creado democráticamente. De ahí que ninguna norma puede ser declarada inconstitucional si ésta admite una interpretación conforme con la Constitución. Como puede advertirse, la declaratoria de inconstitucional es el último recurso que tiene el juez constitucional, cuando de las interpretaciones posibles de la norma infraconstitucional, ninguna de ellas haga compatible la ley con la norma fundamental.

4. Interpretación conforme con la Constitución y con los tratados internacionales. El criterio interpretativo aplica no solamente a la norma constitucional, sino también al derecho convencional;:23 esto es, las normas infraconstitucionales nacionales deben ser armonizadas también con los tratados internacionales que México ha suscrito y que contienen derechos humanos; de esta forma se crea un amplísimo bloque de constitucionalidad extendido a todos los tratados firmados por nuestro país. De ahí que si una norma tildada de inconstitucional admite una interpretación armoniosa con alguna disposición convencional, debe preferirse esta interpretación para evitar la expulsión de la ley infraconstitucional.

5. El objeto materia de la interpretación lo constituyen los derechos humanos contenidos en las normas constitucionales y convencionales, pero también los derechos contenidos en todas las normas de carácter inferior a la Constitución; es decir, el objeto de la armonización conforme abarca el contenido total de los derechos humanos con independencia de estar o no constitucionalizados o incorporados en el derecho internacional; incluso en los últimos años esta tendencia protectora de maximización de los derechos humanos ha tenido una expansión importante en el ámbito estatal

22 Figueroa Mejía, Giovanni A., op. cit., p. 49.

23 El reconocimiento de los derechos humanos contenidos en los tratados internacionales como fuente de derecho nacional es otro de los grandes aportes de la reforma constitucional al artículo 1o. en México, y con ello se da cumplimiento a la Convención de Viena sobre el Derecho de los Tratados (1969), vigente en México a partir del 27 de enero de 1980. 
en México, en donde se han incorporado derechos que no necesariamente se encuentran reconocidos en las normas constitucionales. ${ }^{24}$

6. Vinculación con el principio pro persona. La cláusula de interpretación conforme mantiene una fuerte vinculación con el principio pro homine. Ello implica favorecer en todo tiempo a las personas la protección más amplia de sus derechos. ${ }^{25}$ En opinión de José Luis Caballero Ochoa, el principio pro persona cumple con dos objetivos: a) definir el estándar de integración normativa; es decir, construir el contenido constitucionalmente declarado de los derechos al que alude el Tribunal Constitucional español, y b) señalar la norma aplicable en caso de antinomias, y con independencia de su posición jerárquica; respetando el contenido mínimo esencial del derecho que debe restringirse si se trata de dos normas constitucionales. ${ }^{26}$

\section{EL PRINCIPIO DE INTERPRETACIÓN CONFORME Y SU TÉCNICA DE APLICACIÓN POR LOS JUECES MEXICANOS}

La gran interrogante es cómo deberán enfrentar los jueces mexicanos la facultad de ejercer el control difuso de constitucionalidad, bajo qué parámetros, qué límites impone el ejercicio de esta atribución, cuáles técnicas argumentativas deben ser utilizadas y cómo evitar la expulsión de ordenamientos jurídicos por meras sospechas de inconstitucionalidad, en contravención con la cláusula de interpretación conforme.

24 Nayarit es un ejemplo de ello, que ha incorporado un catálogo de derechos sociales propio de esta entidad distintos a los reconocidos en la Constitución federal; por ejemplo, el derecho a conocer la información genómica, derecho a la atención médica gratuita de los adultos mayores, entre otros. Véase el artículo 7o. de la Constitución Política del Estado de Nayarit.

25 Así, lo previsto en el numeral 29 de la CADH, relativo a que ninguna disposición de ese tratado puede interpretarse para "excluir otros derechos y garantías que son inherentes al ser humano o que deriven de la forma democrática representativa de gobierno" o "excluir o limitar el efecto que puedan producir la declaración americana de derechos y deberes del hombre y otros actos internacionales de la misma naturaleza" o "limitar el goce y ejercicio de cualquier derecho o libertad", deben considerarse en la "interpretación conforme" que se realice en términos del artículo 1o. constitucional.

26 Caballero, José Luis, "La cláusula de interpretación conforme y el principio pro persona (artículo 1o., segundo párrafo, de la Constitución)”, en Carbonell, Miguel y Salazar, Pedro (coords.), La reforma constitucional de derechos humanos: un nuevo paradigma, México, UNAM, Instituto de Investigaciones Jurídicas, 2011, p. 130. 
En adelante, se pretende plantear algunos parámetros metodológicos que puedan servir a los juzgadores mexicanos para ejercer la facultad de control difuso de constitucionalidad, respetando el principio de interpretación conforme, y por ende, evitar incurrir en el ejercicio de esta atribución en violaciones constitucionales, por una inadecuada técnica de aplicación del principio constitucional.

\section{Requisitos previos}

La cláusula de interpretación conforme exige para su observancia tener en cuenta una serie de pasos previos para realizar el examen de constitucionalidad de la ley impugnada. Es decir, presume la existencia de principios que se encuentran vinculados al de interpretación conforme, que necesariamente son de agotamiento anterior a la posibilidad de declarar la inconstitucionalidad de la norma.

En esta línea, las siguientes argumentaciones se orientan a analizar estos requisitos previos para la adecuada observancia del principio de interpretación conforme, como son la unidad del ordenamiento jurídico, presunción de constitucionalidad y conservación del derecho.

\section{Unidad del ordenamiento jurídico}

El sistema jurídico de un Estado constitucional está organizado a través de una unidad normativa, coherente, cohesionado y alineado a una norma principal, en este caso la Constitución. Kelsen sostiene que dicha alineación a una norma de cierre del ordenamiento jurídico permite armonizar y cohesionar el sistema jurídico bajo un parámetro de alineación jerárquica de tipo vertical, donde la Constitución se ubica en el vértice de la pirámide normativa. $^{27}$

Partiendo de este axioma, la unidad del ordenamiento jurídico hace de la Constitución una norma de carácter supremo, que permite darle unidad y validez al sistema normativo secundario de un Estado constitucional, de ahí "que la Constitución es una norma suprema, significa sólo y no es poco, que ésta no puede ser violada por los poderes públicos". ${ }^{28}$

27 Kelsen, Hans, Teoría general del derecho y del Estado, trad. de Eduardo García Máynez, México, UNAM, Instituto de Investigaciones Jurídicas, 1988.

28 Prieto Sanchís, Luis, Justicia constitucional y derechos fundamentales, Madrid, Trotta, 2003, p. 149. 
Así es que Gilmar Ferreira Mendes entiende que la unidad del ordenamiento jurídico otorga validez a la interpretación conforme a la Constitución, pues "las leyes y las normas secundarias deben interpretarse obligatoriamente en consonancia con la Constitución". ${ }^{29}$

En función de esta unidad del ordenamiento jurídico, las leyes emanadas bajo la vigencia de la norma suprema deben ser interpretadas en concordancia con la Constitución. Pues es justamente este requisito el que permite considerar a un conjunto normativo como un sistema jurídico propiamente dicho.

"Efectivamente, la unidad total del ordenamiento ha de inspirarse en la unidad constitucional". ${ }^{30}$ Invariablemente la interpretación de las normas infraconstitucionales tienen como parámetro interpretativo a la norma fundamental, y en consecuencia reconoce que la disposición normativa a interpretar forma parte de un todo, y no puede ser aislado su análisis, porque sería desconocer la pertenencia de la norma al sistema jurídico respectivo.

De tal suerte que el operador jurídico, léase juez, al hacer el estudio de constitucionalidad debe reconocer que la interpretación de determinada disposición normativa puede tener implicaciones que impacten el sistema jurídico completo, y para ello es necesario recurrir a argumentos como el sistemático y de coherencia, para evitar la exclusión de otras disposiciones normativas pertenecientes al sistema. ${ }^{31}$

En síntesis, se puede afirmar que el principio de unidad del ordenamiento jurídico infiere la necesidad de interpretar las disposiciones infraconstitucionales observando el sistema jurídico completo, donde la referencia de cierre del sistema se ubica en la norma constitucional.

\section{Presunción de constitucionalidad}

Otro de los requisitos previos para observar la cláusula de interpretación conforme es la relativa a la condición de considerar a la norma sometida a control como una norma presumiblemente constitucional.

El criterio de presunción de constitucionalidad parte del principio de que la norma infraconstitucional goza de una presunción juris tantum; esto es,

29 Citado por Da Silva, Virgilio Alfonso, op. cit.

30 Figueroa Mejía, Giovanni A., op. cit., p. 61.

31 Sobre la tipología de la argumentación constitucional, véase Ezquiaga Ganuzas, Francisco Javier, La argumentación en la justicia constitucional y otros problemas de aplicación e interpretación del derecho, México, Tribunal Electoral del Poder Judicial de la Federación, 2006. 
que el legislador al momento de crearla actuó respetando los parámetros constitucionales; es decir, la norma impugnada es constitucional, salvo prueba en contrario.

Partiendo de esta premisa, el juez constitucional, al momento de realizar el examen de constitucionalidad, no puede actuar en sentido inverso a esta presunción; es decir, la concepción, criterio o postura inicial del juzgador para examinar la ley debe ser que la norma es constitucional; luego, sólo puede entrar al argumento contrario, inconstitucionalidad si encuentra argumentos sólidos, contundentes y únicos que no hagan compatible la norma en estudio con la Constitución. "La presunción de constitucionalidad, por lo tanto, no es más que el comienzo de la argumentación procesal". 32

Ferreres Comella sostiene al respecto:

La presunción de constitucionalidad impone a quien sostiene que el texto de una ley es inconstitucional la carga de argumentar convincentemente que se da una incompatibilidad entre la norma que ese texto expresa y el sistema de normas que el texto constitucional expresa. Cualquier duda acerca de la interpretación correcta de uno u otro texto se resolverá a favor de la ley: in dubio pro legislatore. ${ }^{33}$

En tal sentido, la ley goza de una presunción de constitucionalidad, que debe ser observada por el juzgador, para evitar la expulsión de normas por la mera sospecha de inconstitucionalidad intuitiva del juez. Corresponde entonces al impugnante aportar la argumentación necesaria para desvirtuar tal presunción, y en su caso obtener la declaratoria de inconstitucionalidad pretendida.

En este caso encontramos un problema en el caso mexicano, puesto que el control difuso ahora reiterado a los jueces para ejercer el control de constitucionalidad es de carácter oficioso; es decir, no se requiere que las partes pidan expresamente el estudio de constitucionalidad de una norma, sino que basta que el juez lo advierta, para que tenga la potestad de realizar dicho estudio; entonces, dicha facultad tendrá que ejercerla siempre y cuando encuentre argumentos irrefutables de que la norma no puede ser interpretada en armonía con la Constitución.

32 Sánchez Gil, Rubén, op. cit., p. 394.

33 Ferreres Comella, Víctor, Justicia constitucional y democracia, Madrid, Centro de Estudios Políticos y Constitucionales, 1997, p. 141. 
Es aquí donde se advierten algunos de los inconvenientes más delicados del control difuso de constitucionalidad mexicano, puesto que la poca experiencia de los jueces ordinarios en los asuntos constitucionales, puede llevar a una preocupante inaplicación de normas jurídicas por la mera sospecha de inconstitucionalidad, y con ello provocar un desconocimiento del sistema democrático del ordenamiento jurídico, y por consiguiente la propia violación directa a la Constitución.

La razón que sustenta el principio de presunción de constitucionalidad tiene su origen en el espíritu democrático que debe caracterizar al legislador. Es al mismo tiempo una forma de reducir la histórica tensión entre democracia y justicia constitucional. ${ }^{34}$ Así, "el juez constitucional sólo declara la inconstitucionalidad de la ley cuando su contradicción con la Constitución es clara. Ello significa la aplicación de esa máxima esencial en la jurisdicción constitucional: in dubio pro legislatore, que no es sólo la exigencia de la técnica jurídica, sino también y sobre todo una consecuencia del principio democrático". 35

Hay una fuerte corriente doctrinal que cuestiona este criterio previo de presunción de constitucionalidad, con el argumento de que dicha referencia inmerecida al legislador impide al juzgador declarar la inconstitucionalidad de la norma, porque siempre será posible encontrar un espacio argumentativo para armonizar la norma con la Constitución. Así, Alfonso Virgilio Da Silva sostiene:

De esta forma, aquéllos que aceptan lo que se ha escrito sobre la presunción de constitucionalidad de las leyes y sobre la interpretación conforme a la Constitución y que sean mínimamente coherentes con los argumentos que suelen traerse a propósito, se darán cuenta rápidamente de que la idea de control de constitucionalidad y la interpretación conforme a la Constitución dejan de tener mucho sentido, pues será difícil no encontrar un argumento por simple que sea, que no sostenga la presunción de constitucionalidad de una ley y, consecuentemente, la exigencia de una interpretación conforme a la Constitución. ${ }^{36}$

34 Sobre la objeción contramayoritaria de la justicia constitucional, véase Gargarella, Roberto, La justicia frente al gobierno. Sobre el carácter contramayoritario del Poder Judicial, Barcelona, Ariel, 1996.

35 Aragón, Manuel, Constitución y democracia, Madrid, Tecnos, 1989, p. 124.

Da Silva, Virgilio Alfonso, op. cit., p. 11. 
Sin embargo, habría que considerar que la presunción de constitucionalidad de la norma no limita al juzgador a ejercer con plenitud de jurisdicción la facultad de enjuiciar la obra legislativa, sino que impone únicamente el deber del juez constitucional de aportar argumentos robustos para sustentar una decisión que implique desconocer la norma por inconstitucional. Es entonces, un principio de argumentación procesal que infiere la pertinencia de que la posición inicial del juez oscila en presumir la constitucionalidad de la norma, salvo prueba en contrario, que se configuran con argumentos objetivamente evidentes para refutar este beneficio de la duda a favor del legislador. "El beneficio de la duda otorgado al legislador, en todo caso y simplemente, es una consideración al ejercicio de una función constitucional análoga a la otorgada a cualquier otro demandado, no una genuflexión". ${ }^{37}$

Por otra parte, también puede considerarse que la presunción de constitucionalidad evita anticipar o precipitar criterios del juzgador constitucional, que comprometan interpretaciones futuras que no hubo la oportunidad de reflexionar con mayor profundidad al momento de realizarse el examen de constitucionalidad. Es decir, una declaratoria de inconstitucionalidad sin argumentos sólidos y objetivamente robustos puede favorecer el error interpretativo. Indudablemente que, como toda obra humana, el error siempre estará latente, lo que aconseja la presunción de constitucionalidad es una forma prudente del juzgador: en caso de duda sobre la constitucionalidad de la norma siempre hay que inclinarse a favor de la validez de la norma y no en el sentido contrario. Esto ayuda a evitar errores y facilita al mismo tiempo su corrección; en consecuencia, "en caso de duda acerca de la constitucionalidad de una ley, el tribunal presuma su validez, pues de este modo los posibles errores que cometa podrán corregirse posteriormente y con mayor facilidad", ${ }^{38}$ en nuevas interpretaciones, con análisis y argumentos que tal vez no se tengan en un primer momento de reflexión constitucional.

\section{Conservación de la obra del legislador}

El principio de conservación del derecho es otro de los presupuestos que debe observar el juez constitucional al momento de realizar la confronta entre una ley y la Constitución. Conservar el derecho implica la necesidad

38 Figueroa Mejía, Giovanni A., op. cit., p. 77. 
de hacer que prevalezcan las normas jurídicas impugnadas cuando estas admitan una interpretación conforme a la Constitución, y de esta forma, evitar el horror vacui; "se dice a menudo que esta doctrina responde al principio general de conservación de los actos jurídicos: es deseable evitar el vacío que supone la expulsión de la ley del ordenamiento, por lo que es preferible interpretar el texto legal de modo que se evite ese efecto". ${ }^{39}$

Por consiguiente, previo a declarar la inconstitucionalidad de la ley, el juez debe buscar por todos los métodos interpretativos a su alcance la concordancia de la ley con la Constitución.

Si el derecho se compone de relaciones jurídicas positivas, es decir, el derecho vigente, se concluye afirmando que el objeto fundamental de cualquier operador jurídico habrá de consistir, precisamente, en el mantenimiento de la vigencia del derecho, toda vez que conservarlo subyace como medio idóneo para asegurar la certeza que antes hemos descrito. Por ello, todo intérprete de la Constitución debe, en primer término, aplicar las disposiciones de la misma con la pretensión de afirmar en el tiempo la fuerza normativa de los preceptos que la componen y promover así la seguridad jurídica recalcada fundamentalmente por el Tribunal Constitucional. ${ }^{40}$

En efecto, observar el principio de conservación del derecho permite al juez constitucional emprender una interpretación conforme a la Constitución, para evitar incurrir en un problema adicional, que necesariamente se produce con la expulsión de la norma inconstitucional; esto es, evita caer en un espacio lagunoso del derecho. La declaratoria de inconstitucionalidad de la ley produce un efecto al mismo tiempo grave para el juez, puesto que ahora aparece un inconveniente adicional: el vacío normativo que debe llenar aplicando otros métodos argumentativos para colmar la laguna. Por tanto, el juez constitucional, más que ningún otro, está interesado en salvaguardar en toda su integridad el ordenamiento constitucional, puesto que su misión esencial descansa, precisamente, en esa salvaguardia. El horror vacui constituye, en definitiva, la causa eficiente inmediata del proceder del tribunal. ${ }^{41}$

El principio de conservación del derecho, contemplado desde un punto de vista teórico, coincide con una exigencia práctica: intentar en la medida

39 Ferreres Comella, Víctor, op. cit., p. 37.

40 Canosa Usera, Raúl, Interpretación constitucional y fórmula politica, Madrid, Centro de Estudios Constitucionales, 1988, p. 186.

41 Ibidem, p. 200. 
de lo "posible", por vía interpretativa, huir del vacío que se provoca cuando una disposición legal se declara nula. ${ }^{42}$ Este problema puede agudizarse en el caso del control abstracto de constitucionalidad, cuando la expulsión de la ley tiene efectos generales y el legislador retarda corregir la norma por la vía del proceso legislativo; en tal caso el riesgo de laguna puede permanecer indefinidamente, y provocar con ello un perjuicio mayor a la mera inconstitucionalidad de la norma.

Como se advierte, la conservación del derecho es al mismo tiempo un elemento que contribuye a reducir la tensión entre democracia y justicia constitucional, ya que parte del presupuesto de que el juez constitucional debe buscar preservar la obra legislativa actuando con especial prudencia al momento de decidir sobre la inconstitucionalidad de la ley. Como lo sostiene el célebre jurista estadounidense Thayer: "el juez no debe invalidar todas las leyes que considere inconstitucionales, sino sólo aquellas que lo sean de un modo manifiesto, más allá de toda duda razonable". ${ }^{43}$

En suma, observar el principio de conservación del derecho como presupuesto del estudio de constitucionalidad de las normas infiere reconocer la obra legislativa, garantiza la certeza y seguridad jurídica del ordenamiento legal, y finalmente reduce el carácter contramayoritario de la justicia constitucional; conservar el derecho presupone una legitimidad de la ley, que sólo puede ser desacreditada si se demuestra la supuesta irregularidad constitucional; de lo contrario la norma impugnada debe ser conservada.

\section{TÉCNICA DE APLICACIÓN PARA LOS JUECES MEXICANOS}

El reto de los jueces mexicanos frente a la reforma constitucional en materia de derechos humanos, como se ha dejado constancia, abre un campo fértil para convertirlos en jueces de constitucionalidad. El problema ahora implica establecer los parámetros técnico-metodológicos para que los jueces ordinarios puedan ejercer adecuadamente esta importante facultad de ser garantes plenos de la supremacía constitucional, por una parte inaplicando disposiciones normativas contrarias al texto constitucional, pero respetando los límites que impone el párrafo segundo del artículo 1o. de la Constitución; esto es, observando el principio de interpretación conforme.

42 Figueroa Mejía, Giovanni A., op. cit., p. 88.

43 Citado por Ferreres Comella, Víctor, op. cit., p. 145. 
Corresponde ahora intentar ofrecer una serie de pasos o recomendaciones que pueden ayudar al juzgador al momento de resolver un problema en el que se plantee la inconstitucionalidad de normas, con el propósito de apoyar principalmente a los jueces ordinarios a realizar con prudencia la labor de garante constitucional.

\section{Argumentación para el examen de constitucionalidad}

Uno de los principales tópicos de la labor jurisdiccional es la argumentación de los jueces, para resolver una controversia jurídica concreta. Sostiene Wróblewski que motivar una decisión judicial significa proporcionar argumentos que la sostengan. ${ }^{44}$ Esto es, toda decisión de los jueces debe ofrecer argumentos racionales, convincentes y persuasivos, fundados en normas jurídicas, que resuelvan una controversia. Para el caso que nos ocupa, la argumentación judicial para resolver sobre la constitucionalidad de una norma está tasada por reglas impuestas por la propia Constitución. La primera de las reglas se refiere al parámetro de supremacía constitucional, ninguna norma jurídica puede estar por encima de la Constitución, dicho de forma simple. ${ }^{45}$ Pero ¿qué implica esta regla?, ¿cómo advertir que la norma impugnada de inconstitucionalidad termina siéndolo? Es aquí donde aparece una segunda regla constitucional: la interpretación; es decir, las normas jurídicas no siempre de su literalidad pueden referir claramente su concordancia o no con la Constitución, sino que se requiere un proceso interpretativo previo de la norma impugnada y de la propia norma constitucional para determinar si existe la antinomia. Incluso el proceso interpretativo, para el caso del control difuso de constitucionalidad, ocurre a partir de un contexto de aplicación de la norma a un caso concreto; esto es, la norma entra en conflicto con la Constitución en el momento en que dicha norma pretende ser aplicada a un caso en particular, y es ahí donde se advierte la posibilidad de que la misma sea contraria a la constitucional; por tanto, la labor interpretativa no siempre se da en forma abstracta, sino que para el caso mexicano esta puede ser en forma concreta, propia del modelo difuso de control de constitucionalidad.

44 Citado por Ezquiaga Ganuzas, Francisco Javier, op. cit., p. 36.

45 Artículo 133 de la Constitución Política de los Estados Unidos Mexicanos. 
La tercera regla que debe reconocer el juzgador es la relativa al criterio de interpretación conforme, con todo lo que infiere respetar este principio, como se ha advertido líneas arriba, evitar en la medida de lo posible las consecuencias que acompañan a la declaratoria de inconstitucionalidad, como por ejemplo el horror vacui, conservar el derecho vigente y presumir la constitucionalidad de la norma.

Ahora bien, una vez observadas las reglas previas al examen de constitucionalidad, el juez puede determinar el conflicto de constitucionalidad observando los siguientes parámetros:

1. Identificar la antinomia. La primera actividad consiste en identificar la antinomia entre la norma inferior y la Constitución. Guastini identifica a la antinomia de dos modos: a) en un sistema jurídico, existe una antinomia siempre que un determinado comportamiento esté deónticamente calificado de dos modos incompatibles en dos diversas normas pertenecientes al sistema, o b) en un sistema jurídico existe una antinomia siempre que para un determinado supuesto de hecho estén previstas dos consecuencias jurídicas incompatibles por dos normas diversas pertenecientes al sistema. ${ }^{46} \mathrm{El}$ problema principal, en tal caso, es identificar la posibilidad de antinomia entre la norma objetada con la norma constitucional: esto es un problema nada fácil de resolver, puesto que las antinomias no siempre aparecen de forma evidente, que permita identificarlas de la sola literalidad del precepto. Existen antinomias que pueden derivarse de la propia literalidad de los preceptos, lo cual no sería tan complicado identificarlas; en cambio, pueden identificarse antinomias difíciles de advertir, como aquellas que sólo se producen de la interpretación o aplicación de los preceptos a casos concretos. Para tal efecto, habría que advertir en dónde radica la duda de inconstitucionalidad; es decir, la antinomia; la duda de inconstitucionalidad puede surgir de: a) la literalidad del precepto legal impugnado, b) de su interpretación, o c) de la aplicación de la norma al caso concreto.

a) De la literalidad del precepto. En este caso, la antinomia puede deducirse del contenido literal de la disposición normativa impugnada, que infiere una contradicción con la norma constitucional, normas incompatibles, siguiendo el método de Guastini, sea porque un comportamiento esté regulado de forma incompatible entre la norma infraconstitucional y la Constitución, o bien que el comportamiento regulado contenga consecuencias jurídicas

46 Guastini, Riccardo, Estudios sobre la interpretación jurídica, trad. de Marina Gascón y Miguel Carbonell, México, Porrúa, 2010, p. 7. 
incompatibles por la norma impugnada y la Constitución. Este primer supuesto pudiera deducirse de la mera literalidad de los preceptos en pugna, siempre que se evidencie con claridad la antinomia.

b) De su interpretación. Así como la antinomia puede prevenirse por medio de la interpretación jurídica, también la interpretación puede provocarla. En tal caso, habría que reflexionar sobre la utilización de métodos interpretativos adecuados para evitar la antinomia o en su caso generarla. Debe decirse que en este tópico, una forma de evitar la antinomia es la utilización de técnicas interpretativas idóneas, como lo recomienda el propio Guastini; algunas de ellas podrían ser la interpretación adecuadora y la interpretación restrictiva. Se llama interpretación adecuadora aquélla que adapta, adecua el significado de una disposición a un principio o a una norma de rango superior (Constitución), de modo que evite el surgimiento de conflictos. Por su parte, la interpretación restrictiva tiene el efecto de excluir del campo de aplicación de una cierta norma un determinado supuesto de hecho que, interpretado diversamente, entraría en ese campo. ${ }^{47}$

c) De la aplicación de la norma al caso concreto. Por otra parte, la antinomia puede surgir al momento en que la norma infraconstitucional tiene efectos jurídicos concretos en un acto de aplicación. Este momento sería el más recurrente en el control difuso de constitucionalidad, porque la duda de constitucionalidad, y su consecuente impugnación, ocurre cuando la norma infraconstitucional es aplicada.

2. Interpretar la norma con los métodos ordinarios. Como se sostiene líneas arriba, la interpretación jurídica puede evitar la antinomia o en su caso provocarla; para el caso del examen constitucional de la ley impugnada, el juzgador debe realizar su labor interpretativa mediante la utilización de métodos y técnicas interpretativas ordinarios; esto es, que sean los adecuados para dilucidar cualquier problema interpretativo. De ahí que, si de la utilización de los métodos interpretativos ordinarios se advierte la posible antinomia, será necesario agotar lo siguiente.

3. Resultado de la interpretación. Si del adecuado uso de los métodos interpretativos produce en un primer ejercicio la conclusión de que la norma es inconstitucional, el juzgador no puede, atendiendo al principio de interpretación conforme, provocar inmediatamente la declaratoria de inconstitucionalidad; por el contrario, debe reflexionar, cuestionarse, intentar si la norma puede ser interpretada de manera conforme a la Constitución. 
Este ejercicio amerita un esfuerzo reflexivo profundo, valorar si la técnica interpretativa usada es suficientemente sólida para arribar a la inconstitucionalidad, incluso evaluar la posibilidad del error argumentativo del juez, "por una parte, puede ocurrir que invalide una ley que, en realidad, tras una reflexión más profunda a la luz de nuevos datos y argumentos, aparece como perfectamente constitucional. Por otra, puede suceder que el juez declare válida una ley que en realidad, es inconstitucional, como aparece tras una mayor reflexión". ${ }^{48}$ Es claro que la posibilidad del error de la decisión judicial siempre estará latente; sin embargo, será necesaria una argumentación robusta que justifique la decisión.

Por otra parte, el resultado de la interpretación puede ser que la norma admita dos interpretaciones válidamente posibles, pero incompatibles entre sí; esto es, que por una parte se produzca una interpretación que indica la inconstitucionalidad, y otra que admita la constitucionalidad; en tal caso, el problema se resuelve prefiriendo la interpretación conforme a la Constitución. Ahora bien, decir que deben ser "interpretaciones válidamente posibles" significa que sean el resultado natural de la utilización de métodos y técnicas interpretativas que producen orientaciones incompatibles sobre un mismo problema, no se trata de forzar una interpretación opuesta para evitar la inconstitucionalidad. Deben surgir ambas interpretaciones como resultado de un proceso interpretativo normal.

Si el único resultado interpretativo de la norma conduce a determinar la inconstitucionalidad, el juzgador debe argumentar en su decisión que no fue posible encontrar una interpretación conforme a la Constitución, y por consiguiente es necesario determinar la inconstitucionalidad, esto con el propósito de justificar en la decisión que el juez constitucional sí estuvo pendiente de salvar la validez de la norma impugnada, y por ende atendió el principio de interpretación conforme.

Ahora bien, el proceso de decisión de inconstitucionalidad debe ser cuidadoso para evitar que se expulsen del ordenamiento jurídico disposiciones normativas que sí son compatibles con la Constitución. No necesariamente toda la disposición normativa puede resultar incompatible, sino sólo algunos enunciados, frases o palabras, pero el demás contenido debe preservarse; de ahí que la labor del juez constitucional estribe en determinar cuáles porciones normativas deben ser eliminadas de la norma, y en su caso preservar aquellos enunciados que no son contrarios a la Constitución. Invalidar todo

48 Ferreres Comella, Víctor, op. cit., p. 200. 
el precepto normativo representaría violentar al mismo tiempo el principio de supremacía constitucional.

4. Los casos de duda. Con seguridad el juez puede encontrarse casos dudosos en los que el problema de inconstitucionalidad o constitucionalidad no permita ser determinado con certeza o claridad argumentativa. En tales condiciones, atendiendo al principio de presunción de constitucionalidad, el juez deberá preferir la constitucionalidad de la norma como alternativa de solución al conflicto planteado. "Que la ley se beneficie de una presunción de constitucionalidad quiere decir que sólo cuando existen suficientes argumentos en contra de la misma puede el juez dar el paso de invalidarla". ${ }^{49}$ Como se ha sostenido en este trabajo, la decisión de determinar la invalidez de la norma requiere argumentos robustos que destruyan la presunción de la que gozan las leyes, y mientras no se tengan dichos argumentos, la duda favorecerá la presunción de constitucionalidad y tendrá como resultado la validez de la norma impugnada.

\section{Las sentencias interpretativas. Una forma de equilibrar el debate}

Ante los dilemas que se presentan por la observación del principio de interpretación conforme, los jueces constitucionales pueden producir sentencias interpretativas, en su intento por salvar la constitucionalidad de la ley. Con frecuencia este tipo de sentencias producen resultados interpretativos respecto a la ley, que sirven de orientaciones para los siguientes análisis sobre la misma disposición normativa; en algunos casos, como ocurre en México, estos precedentes resultan obligatorios para todos los tribunales cuando son emitidos por la Suprema Corte de Justicia de la Nación.

Por lo regular, cuando los jueces constitucionales resuelven la validez de la norma atendiendo al principio de interpretación conforme, como resultado de dos interpretaciones válidamente posibles, pero contradictorias entre sí, son conscientes de que existen elementos también sólidos para sostener la inconstitucionalidad de la norma, y se ven en la incómoda disyuntiva de preferir la interpretación que haga compatible a la norma con la Constitución, pero son sensatos en el sentido de que la norma tiene un indicio de inconstitucionalidad. 
Una forma de resolver este dilema son las llamadas sentencias interpretativas, entendidas éstas como "aquellas que emiten un pronunciamiento, no sobre el enunciado de la ley sino sobre una norma que de él puede deducirse mediante el empleo de los métodos habituales de interpretación". ${ }^{50}$ Las sentencias interpretativas permiten salvar la validez de la norma, pero dejan constancia argumentativa de que alguna de las interpretaciones posibles de la norma impugnada puede ser entendida en sentido inconstitucional. De esta forma, Díaz Revorio sostiene al respecto que las sentencias interpretativas "son aquellas, recaídas en un procedimiento de inconstitucionalidad, cuyo fallo, dejando inalterado el texto de la disposición, declara explícita o implícitamente que al menos una de las normas, o parte de ella, que de él deriva conjunta o alternativamente, no son acordes con la Constitución". ${ }^{51}$

Este tipo de sentencias permiten advertir aquellas interpretaciones que fueron desechadas por el juez constitucional que determinaban la incompatibilidad de la norma con la Constitución, pero que por atender el principio de interpretación conforme no fueron atendidas; sin embargo, la argumentación interpretativa que se produce resulta ampliamente valiosa. Regularmente estas interpretaciones no se encuentran en la parte final del fallo de la sentencia, sino en la parte considerativa que lo precede. Estos precedentes, sin duda, pueden servir como orientaciones válidas para futuras discusiones en las que sea sometida a control de nueva cuenta la ley impugnada, para advertir la consistencia evolutiva de los argumentos previos.

\section{Los riesgos de las sentencias manipulativas. ¿De legislador} negativo a legislador positivo?

Otro de los resultados que puede producir la sentencia de los jueces constitucionales es, por una parte, la declaratoria de constitucionalidad parcial de la norma impugnada, y, por la otra, la inconstitucionalidad de porciones o enunciados normativos. A este tipo de sentencias, la doctrina italiana les denomina "manipulativas", y por tales podemos entender "aquellas que declaran, explícita o implícitamente, la inconstitucionalidad de parte del contenido normativo derivado de forma conjunta o compleja de una dis-

50 Rubio Llorente, Francisco, La forma del poder (estudios sobre la Constitución), Madrid, Centro de Estudios Constitucionales, 1993, p. 516.

51 Citado por Figueroa Mejía, Giovanni A., op. cit., p. 97. 
posición normativa, produciendo el efecto de modificar o innovar dicho contenido normativo". ${ }^{5}$

En este tipo de sentencias, el juez constitucional, al desprender de la norma aquellas porciones que resultan inconstitucionales y dejar las compatibles con la Constitución, prácticamente cambia el sentido de la norma, su redacción y, por consiguiente, el contenido, convirtiéndose de un legislador negativo a uno de carácter positivo o colegislador. Existen en la doctrina fuertes críticas al respecto, sobre este tipo de sentencias, que consideran el actuar del juez constitucional como violatorio del principio de división de poderes, que es el fundamento mismo de toda la arquitectura constitucional. ${ }^{53}$ Y con ello se ahonda más el debate sobre el carácter contramayoritario de la justicia constitucional.

Recientemente, la Primera Sala de la Suprema Corte de Justicia de la Nación, en el amparo en revisión 581/2012, ${ }^{54}$ resolvió un asunto en el que se demandó la inconstitucionalidad del artículo 143 del Código Civil de Oaxaca, por considerar que dicho precepto viola el principio de igualdad y genera discriminación hacia las personas del mismo sexo que deciden contraer matrimonio. En este caso se dicta una sentencia manipulativa, puesto que por una parte se armoniza una porción normativa del artículo $143 \mathrm{del}$ Código Civil de Oaxaca, que establece el concepto de matrimonio, y por otra elimina aquellas porciones del precepto que considera inconstitucionales, produciéndose un nuevo enunciado normativo.

El enunciado normativo del referido precepto dispone "El matrimonio es un contrato civil celebrado entre un solo hombre y una sola mujer, que se unen para perpetuar la especie y proporcionarse ayuda mutua en la vida". Después de las consideraciones y argumentos vertidos en la sentencia, la Corte determina que el precepto anterior debe quedar de la siguiente manera: "el matrimonio es un contrato civil celebrado entre dos personas para proporcionarse ayuda mutua en la vida". ${ }^{55}$

Como se puede advertir, la sentencia manipulativa pretende salvar los enunciados normativos compatibles con la Constitución y elimina aquellos que considera inconstitucionales, pero el resultado que se produce es la

52 Ibidem, p. 147.

53 Véase Rubio Llorente, Francisco, op. cit., p. 522.

54 La sentencia puede consultarse en http://www2.scjn.gob.mx/ConsultaTematica/Pa ginasPub/DetallePub.aspx?AsuntoID=143969.

55 Idem. 
generación de una nueva norma jurídica que no fue concebida por el legislador, convirtiéndose el juez constitucional en un colegislador o legislador positivo. Este deslizamiento, que ha permitido al legislador negativo asumir la función del legislador a secas, es paradójicamente el resultado final, no necesario, pero posible, de una construcción teórica dominada por la preocupación de mantener la sujeción del juez a la ley. ${ }^{56}$

\section{CONCLUSIÓN}

El reto de los jueces mexicanos frente a la reforma constitucional en materia de derechos humanos, como se ha dejado constancia, abre un campo fértil para convertirlos en jueces de constitucionalidad. El problema ahora implica establecer los parámetros técnico-metodológicos para que los jueces ordinarios puedan ejercer adecuadamente esta importante facultad de ser garantes plenos de la supremacía constitucional, por una parte inaplicando disposiciones normativas contrarias al texto constitucional, pero respetando los límites que impone el párrafo segundo del artículo 1o. de la Constitución; esto es, observando el principio de interpretación conforme.

Desconocer el funcionamiento del control difuso de constitucionalidad, por parte de los jueces mexicanos, puede traer consecuencias dañinas al propósito perseguido con la reforma, al no lograrse comprender con claridad que la posibilidad de los jueces para desaplicar una ley ordinaria al caso concreto, en aras de proteger la Constitución, tiene límites o parámetros que deben ser observados por los juzgadores, antes de tomar la decisión de inobservar una disposición legal que tilde de inconstitucional; uno de estos límites es la interpretación conforme.

\section{FUENTES DE CONSULTA}

\section{Bibliografia}

Aragón, Manuel, Constitución y democracia, Madrid, Tecnos, 1989.

CABALlero, José Luis, "La cláusula de interpretación conforme y el principio pro persona (artículo 1o., segundo párrafo, de la Constitución)",

56 Rubio Llorente, Francisco, op. cit., p. 523. 
en CARBonell, Miguel y SalaZAR, Pedro (coords.), La reforma constitucional de derechos humanos: un nuevo paradigma, México, UNAM, Instituto de Investigaciones Jurídicas, 2011.

CANOSA USERA, Raúl, Interpretación constitucional y fórmula política, Madrid, Centro de Estudios Constitucionales, 1988.

Cossío, José Ramón, La teoría constitucional de la Suprema Corte de Justicia, México, Fontamara, 2002.

Da Silva Virgilio, Alfonso, "La interpretación conforme a la Constitución. Entre la trivialidad y la centralización judicial", Cuestiones Constitucionales, Revista Mexicana de Derecho Constitucional, México, núm. 12, enero-junio de 2005.

El Federalista, trad. de Gustavo R. Velasco, México, Fondo de Cultura Económica, 2000, núm. LXXVIII.

EZQUiAga GANUZAS, Francisco Javier, La argumentación en la justicia constitucional y otros problemas de aplicación e interpretación del derecho, México, Tribunal Electoral del Poder Judicial de la Federación, 2006.

FERRER MAC-GREGOR, Eduardo, Interpretación conforme y control difuso de convencionalidad, el nuevo paradigma para el juez mexicano, México, UNAM, Instituto de Investigaciones Jurídicas, http://www.conatrib. org. $\mathrm{mx} / \mathrm{html} /$ Paneles/Paneles/PanelVIII_Interpretaci\%C3\%B3nConfo rmeControlDifusoConvencionalidad_EduardoFerrer.pdf.

y ZALDÍvAR LELO DE LARREA, Arturo (coords.), La ciencia del derecho procesal constitucional. Estudios en homenaje a Héctor FixZamudio en sus cincuenta años como investigador del derecho, México, UNAM, Instituto de Investigaciones Jurídicas, 2008, t. VI.

FERRERES COMELLA, Víctor, Justicia constitucional y democracia, Madrid, Centro de Estudios Políticos y Constitucionales, 1997.

FigueroA MeJíA, Giovanni A., Las sentencias constitucionales atípicas en el derecho comparado y en la acción de inconstitucionalidad mexicana, México, Porrúa, 2011.

GARGARElla, Roberto, La justicia frente al gobierno. Sobre el carácter contramayoritario del Poder Judicial, Barcelona, Ariel, 1996.

GUASTINI, Riccardo, Estudios sobre la interpretación jurídica, trad. de Marina Gascón y Miguel Carbonell, México, Porrúa, 2010. 
KELSEN, Hans, Teoría general del derecho y del Estado, trad. de Eduardo García Máynez, México, UNAM, Instituto de Investigaciones Jurídicas, 1988.

PRIETO SANCHÍs, Luis, Justicia constitucional y derechos fundamentales, Madrid, Trotta, 2003.

RuBio LloRENTE, Francisco, La forma del poder (estudios sobre la Constitución), Madrid, Centro de Estudios Constitucionales, 1993.

\section{Legislación}

Constitución Política de Colombia.

Constitución Política de los Estados Unidos Mexicanos.

Constitución Política del Estado de Nayarit.

\section{Medios electrónicos}

http://www.juridicas.unam.mx/.

http://www.diputados.gob.mx/inicio.htm.

http://www.congresonayarit.mx/Inicio.aspx.

Fecha de recepción: 18 de noviembre de 2014.

Fecha de dictamen: 1 de diciembre de 2014. 